\title{
Predictors of second-sided deep brain stimulation for Parkinson's disease
}

\author{
Joshua L. Golubovsky, BS, ${ }^{1}$ Hong Li, MS, ${ }^{2}$ Arbaz Momin, BS, ${ }^{1}$ Jianning Shao, BA, ${ }^{1}$ \\ Maxwell Y. Lee, BS, ${ }^{1}$ Leonardo A. Frizon, MD, ${ }^{3}$ Olivia Hogue, MPH, ${ }^{2}$ Benjamin Walter, MD, ${ }^{3,4}$ \\ André G. Machado, MD, PhD, ${ }^{3,5}$ and Sean J. Nagel, MD ${ }^{3,5}$ \\ ${ }^{1}$ Cleveland Clinic Lerner College of Medicine of Case Western Reserve University, Education Institute; ${ }^{2}$ Department of \\ Quantitative Health Sciences, Lerner Research Institute, Cleveland Clinic; and ${ }^{3}$ Center for Neurological Restoration, and \\ Departments of ${ }^{4}$ Neurology and ${ }^{5}$ Neurosurgery, Neurological Institute, Cleveland Clinic, Cleveland, Ohio
}

OBJECTIVE Parkinson's disease (PD) is a progressive neurological movement disorder that is commonly treated with deep brain stimulation (DBS) surgery in advanced stages. The purpose of this study was to investigate factors that affect time to placement of a second-sided DBS lead for PD when a unilateral lead is initially placed for asymmetrical presentation. The decision whether to initially perform unilateral or bilateral DBS is largely based on physician and/or patient preference.

METHODS This study was a retrospective cohort analysis of patients with PD undergoing initial unilateral DBS for asymmetrical disease between January 1999 and December 2017 at the authors' institution. Patients treated with DBS for essential tremor or other conditions were excluded. Variables collected included demographics at surgery, time since diagnosis, Unified Parkinson's Disease Rating Scale motor scores (UPDRS-III), patient-reported quality-of-life outcomes, side of operation, DBS target, intraoperative complications, and date of follow-up. Paired t-tests were used to assess mean changes in UPDRS-III. Cox proportional hazards analysis and the Kaplan-Meier method were used to determine factors associated with time to second lead insertion over 5 years.

RESULTS The final cohort included 105 patients who underwent initial unilateral DBS for asymmetrical PD; $59 \%$ of patients had a second-sided lead placed within 5 years with a median time of 34 months. Factors found to be significantly associated with early second-sided DBS included patient age 65 years or younger, globus pallidus internus (GPi) target, and greater off-medication reduction in UPDRS-III score following initial surgery. Older age was also found to be associated with a smaller preoperative UPDRS-III levodopa responsiveness score and with a smaller preoperative to postoperative medication-off UPDRS-III change.

CONCLUSIONS Younger patients, those undergoing GPi-targeted unilateral DBS, and patients who responded better to the initial DBS were more likely to undergo early second-sided lead placement. Therefore, these patients, and patients who are more responsive to medication preoperatively (as a proxy for DBS responsiveness), may benefit from consideration of initial bilateral DBS.

https://thejns.org/doi/abs/10.3171/2019.12.JNS19638

KEYWORDS Parkinson's disease; deep brain stimulation; DBS; asymmetrical; age; Kaplan-Meier analysis; functional neurosurgery

$\mathrm{P}$ ARKINSON's disease (PD) is a debilitating neurodegenerative condition second only to Alzheimer's disease and essential tremor in prevalence. In industrialized countries, the prevalence of PD is estimated to reach $0.3 \%$ of the entire population and $1 \%$ of individuals over the age of 60 years. ${ }^{3} \mathrm{PD}$ is characterized by the triad of tremor, rigidity, and akinesia. ${ }^{9}$ Levodopa (L-dopa) has been prescribed for the treatment of the motor dysfunctions of PD for decades. However, L-dopa will frequently cause dyskinesias (involuntary sudden motor movements) and motor fluctuations with increasingly shorter and inconsistent benefit after years of treatment. ${ }^{9}$

ABBREVIATIONS BMI = body mass index; DBS = deep brain stimulation; EQ-5D = EuroQol-5 Dimensions; GPi = globus pallidus internus; L-dopa = levodopa; MDSUPDRS = Movement Disorder Society revision of Unified Parkinson's Disease Rating Scale; PD = Parkinson's disease; PHQ-9 = Patient Health Questionnaire-9; QOL = quality of life; STN = subthalamic nucleus; UPDRS-II = Unified Parkinson's Disease Rating Scale self-evaluation score; UPDRS-III = UPDRS motor score.

SUBMITTED March 6, 2019. ACCEPTED December 13, 2019.

INCLUDE WHEN CITING Published online February 14, 2020; DOI: 10.3171/2019.12.JNS19638. 
Deep brain stimulation (DBS) for PD has been shown to provide significant benefits in terms of both quality of life (QOL) and mobility for patients who are intolerant of L-dopa therapy. ${ }^{1,4,5,11,14,17,18}$ Patients typically undergo unilateral or bilateral stimulation depending on symptom asymmetry. Although bilateral DBS is more common, a proportion of patients with predominantly unilateral symptoms will undergo unilateral implantation in an attempt to address the patient's symptoms while mitigating surgical risk. There is limited literature indicating the factors that determine time to placement of a second lead, or whether a second lead is placed at all, following unilateral stimulation. Petraglia et al. determined that there are no significant differences in complication rates between bilateral and staged procedures. Furthermore, the procedures are similar in terms of healthcare cost..$^{12}$ Therefore, the decision whether to perform a bilateral or unilateral lead implantation rests with neurological surgeons and their patients, and may be influenced by the relative asymmetry of symptoms as well as patient functional goals and preferences. At our institution this decision is made by a team of neurosurgeons, neurologists, and neuropsychologists during a patient management conference. The decision is based on the patient's presentation (primarily symptom asymmetry), goals, and caregiver experience.

An investigation by Taba et al. of unilateral DBS for PD in 52 patients revealed that $48 \%$ of patients undergoing unilateral stimulation chose not to progress to bilateral stimulation at 6 months postoperatively..$^{15}$ However, this study prospectively examined factors that influenced patient choice whether or not to receive a second lead, and did not fully address preoperative factors such as depression, patient-determined motor function at baseline, and preoperative QOL that may have influenced second lead placement. Additionally, the study only examined the binary outcome of receiving a second lead or not receiving a second lead, and did not examine how preoperative factors impacted timing to second lead placement. The present study aimed to address the preoperative factors that influence time to contralateral lead placement within 5 years of initial surgery in DBS for PD. We hypothesized that patients with worse motor symptoms at baseline, better Ldopa responsiveness, worse baseline QOL and depression, shorter disease duration, and younger age at first surgery would be more likely to receive a second lead and in a shorter time period.

\section{Methods \\ Study Population}

After obtaining approval from our institutional review board, we performed a retrospective cohort analysis of all patients undergoing unilateral DBS for PD at our institution between January 1999 and December 2017. Patients under the age of 18 years and patients with other conditions that affect motor function (such as stroke, malignancy, or neuropathy) were excluded to limit confounding factors in the present study. All patients who underwent DBS for PD in this study were discussed in a patient management conference prior to planning surgery. These conferences were attended by experts in the field at our insti- tution. They determined whether the patient should have unilateral or bilateral lead placement, as well as whether the target should be the subthalamic nucleus (STN) or the globus pallidus internus (GPi).

\section{Data Collection}

Preoperative variables collected included the following: age at surgery; sex; body mass index (BMI); handedness; PD diagnosis date; Unified Parkinson's Disease Rating Scale (UPDRS) motor score (UPDRS-III)/Movement Disorder Society revision of UPDRS (MDS-UPDRS); patient-determined motor function (i.e., UPDRS self-evaluation score [UPDRS-II]); Patient Health Questionnaire-9 (PHQ-9) scores; EuroQol-5 Dimensions (EQ-5D) scores; median income; and ZIP code distance from the Cleveland Clinic main campus. Intraoperative variables included side of surgery, surgical site (STN or GPi), and whether an intraoperative complication occurred. Postoperative variables collected included UPDRS-III/MDS-UPDRS scores, latest date of follow-up, and date of death if applicable.

Collected UPDRS scores were identified as either the older UPDRS-III or as the newer MDS-UPDRS. Hoehn and Yahr scores, when available, were used to convert MDS-UPDRS to UPDRS-III?

\section{Statistical Analysis}

All analyses were performed using SAS version 9.4. Patient demographics and clinical characteristics at baseline (at first DBS) are summarized descriptively with mean, frequency, and percentage. Paired t-tests were used to confirm whether the sample as a whole improved per UPDRS-III from the preoperative off-medication state after the first and second surgeries. Time from initial DBS to second-side DBS or to last contact if no second DBS lead was inserted was calculated, with censoring after 5 years. Two patients died within 5 years and were censored at time of death; death was not considered as a competing risk for a second DBS implant. Numerical variables were grouped into 2 groups based on median values. The Kaplan-Meier method and Cox proportional hazards models were used to determine factors that were potentially associated with no second DBS over 5 years. Median no-second-surgery times and survival curves were based on the Kaplan-Meier method, whereas the hazard ratio of early second DBS was estimated using the Cox model. Statistical significance was set at $\mathrm{p} \leq 0.05$.

\section{Results}

This study included 105 patients diagnosed with PD who underwent unilateral DBS without a preliminary plan for second lead placement (and in whom the first lead was placed between January 1, 1999, and February 20, 2017) out of a total of 1011 patients undergoing unilateral, bilateral, or staged DBS for PD at our institution during this timeframe (10.4\%). The sample was $25 \%$ female, with a mean age of 64 years (SD 8.5 years) and an average of 9.8 years (SD 5.2 years) since PD diagnosis. Sixty-three patients had initial left-sided DBS (60\%) and 42 had initial right-sided DBS (40\%). Table 1 summarizes the demographic data. 
TABLE 1. Patient characteristics at initial DBS

\begin{tabular}{|c|c|c|}
\hline \multirow[b]{2}{*}{ Factor } & \multicolumn{2}{|r|}{ All $(N=105)$} \\
\hline & No. Available & Mean \pm SD or Total No. (\%) \\
\hline Male sex & 105 & $79(75.2 \%)$ \\
\hline Age (yrs) & 105 & $64.0 \pm 8.5$ \\
\hline Age $>65$ yrs & 105 & $51(48.6 \%)$ \\
\hline PD duration (yrs) & 102 & $9.8 \pm 5.2$ \\
\hline PD duration $>9$ yrs & 102 & $49(48.0 \%)$ \\
\hline BMl at first surgery & 105 & $28.0 \pm 5.1$ \\
\hline $\mathrm{BMI}>30$ & 105 & $34(32.4 \%)$ \\
\hline Median income (US\$) & 100 & $53,171.7 \pm 15,809.8$ \\
\hline Rt-hand dom & 105 & $89(84.8 \%)$ \\
\hline Married & 103 & $74(71.8 \%)$ \\
\hline Tobacco use ever & 105 & $36(34.3 \%)$ \\
\hline PHQ-9 score & 46 & $7.6 \pm 5.8$ \\
\hline EQ-5D score & 32 & $0.72 \pm 0.15$ \\
\hline UPDRS-II (patient-scored motor ADL) score & 41 & $15.1 \pm 7.2$ \\
\hline Surgical target & 105 & \\
\hline STN & & $97(92.4 \%)$ \\
\hline GPi & & $8(7.6 \%)$ \\
\hline Surgery side & 105 & \\
\hline $\mathrm{Lt}$ & & $63(60.0 \%)$ \\
\hline Rt & & $42(40.0 \%)$ \\
\hline Surgery side \& dom hand & 105 & \\
\hline Lt-sided surgery, rt-dom & & $59(56.2 \%)$ \\
\hline Rt-sided surgery, It-dom & & $12(11.4 \%)$ \\
\hline Surgery ipsilat to dom hand & & $34(32.4 \%)$ \\
\hline UPDRS preop medication-off & 95 & $37.8 \pm 11.3$ \\
\hline UPDRS preop medication-on & 92 & $21.1 \pm 9.3$ \\
\hline UPDRS postop medication-off/stimulation-on & 88 & $20.8 \pm 9.0$ \\
\hline \multicolumn{3}{|l|}{ UPDRS absolute reduction \& $\%$ reduction } \\
\hline $\begin{array}{l}\text { Absolute reduction of preop medication-off to } \\
\text { medication-on }\end{array}$ & 90 & $17.7 \pm 10.2$ \\
\hline$\%$ reduction of preop medication-off to medication-on & 90 & $45.1 \% \pm 20.1 \%$ \\
\hline $\begin{array}{l}\text { Absolute reduction of preop medication-off to postop } \\
\text { medication-off/stimulation-on }\end{array}$ & 87 & $16.8 \pm 12.7$ \\
\hline $\begin{array}{l}\% \text { reduction of preop medication-off to postop } \\
\text { medication-off/stimulation-on }\end{array}$ & 87 & $41.7 \% \pm 26.1 \%$ \\
\hline
\end{tabular}

Analysis of second DBS insertion within the 5-year follow-up is summarized in Table 2. Sixty-two patients (59\%) had opposite-side DBS within 5 years, and the median time from initial unilateral surgery to second-side surgery was 34 months. Kaplan-Meier analysis revealed a probability of second-sided DBS of $22 \%$ at 12 months, $41 \%$ at 24 months, and $51 \%$ at 36 months. Subjects 65 years of age or younger had almost 3 -fold the risk of second lead placement within 5 years, when compared with subjects older than 65 years $(p=0.005)$ (Fig. 1). The Kaplan-Meier-estimated median time without a second-sided DBS surgery was 29 months for the younger group, whereas more than $50 \%$ of the older group did not receive second-sided DBS at all. At 36 months, the probability of second lead placement was $62.7 \%$ for patients aged 65 years and younger and $39.3 \%$ for those older than 65 years. Those with a GPi target had almost 3 times the risk of second lead placement; all 8 patients who received GPi-targeted DBS had second-sided surgery within 36 months, whereas $53.1 \%$ of those with an STN target had no second-sided DBS at 36 months (log-rank test, $\mathrm{p}=0.01$, Fig. 2). Further analysis of the GPi group showed that in 7 of the 8 patients GPi DBS was recommended because of significant dyskinesias. Six patients later had a contralateral lead implanted to control dyskinesias on the side ipsilateral to the initial lead. The seventh patient had contralateral surgery follow- 
TABLE 2. Factors associated with 5-year no-DBS survival

\begin{tabular}{|c|c|c|c|c|c|c|c|}
\hline \multirow[b]{2}{*}{ Variable } & \multirow{2}{*}{$\begin{array}{l}\text { No. of } \\
\text { Pts }\end{array}$} & \multirow{2}{*}{$\begin{array}{l}\text { DBS w/in } 5 \\
\text { Yrs, No. (\%) }\end{array}$} & \multirow{2}{*}{$\begin{array}{l}\text { KM Est Median Time, } \\
\text { No-DBS Group (mos) }\end{array}$} & \multicolumn{4}{|c|}{ Cox Hazards Model } \\
\hline & & & & Unadj HR (95\% Cl) & $p$ Value & Adj HR (95\% Cl) & $p$ Value \\
\hline Overall & 105 & $62(59)$ & 34 & & & & \\
\hline \multicolumn{8}{|l|}{ Demographics } \\
\hline \multicolumn{8}{|l|}{ Age in yrs } \\
\hline$\leq 65$ & 54 & $40(74)$ & 29 & $2.09(1.24,3.53)$ & 0.006 & $2.78(1.45,5.32)$ & 0.002 \\
\hline$>65$ & 51 & $22(43)$ & & - & & - & \\
\hline \multicolumn{8}{|l|}{ Sex } \\
\hline Female & 26 & $13(50)$ & 42 & - & & & \\
\hline Male & 79 & $49(62)$ & 34 & $1.31(0.71,2.41)$ & 0.39 & & \\
\hline \multicolumn{8}{|l|}{ BMI } \\
\hline$\leq 30$ & 71 & $40(56)$ & 42 & - & & & \\
\hline$>30$ & 34 & $22(65)$ & 24 & $1.32(0.78,2.21)$ & 0.30 & & \\
\hline \multicolumn{8}{|l|}{ Median income } \\
\hline$\leq$ US $\$ 50,000$ & 48 & $26(54)$ & 48 & - & & & \\
\hline$>$ US $\$ 50,000$ & 52 & $34(65)$ & 26 & $1.35(0.81,2.25)$ & 0.25 & & \\
\hline \multicolumn{8}{|l|}{ Dominant hand } \\
\hline $\mathrm{Lt}$ & 16 & $10(63)$ & 29 & $1.28(0.65,2.53)$ & 0.47 & & \\
\hline Rt & 89 & $52(58)$ & 35 & - & & & \\
\hline \multicolumn{8}{|l|}{ Marital status } \\
\hline Other & 29 & $14(48)$ & & - & & & \\
\hline Married & 74 & $47(64)$ & 31 & $1.37(0.75,2.49)$ & 0.30 & & \\
\hline \multicolumn{8}{|l|}{ Tobacco use } \\
\hline Never used & 69 & $40(58)$ & 46 & - & & & \\
\hline Ever used & 36 & $22(61)$ & 31 & $1.00(0.60,1.69)$ & 0.99 & & \\
\hline \multicolumn{8}{|l|}{ Health status measures } \\
\hline \multicolumn{8}{|l|}{ EQ-5D score } \\
\hline$\leq 0.7$ & 14 & $10(71)$ & 8 & $1.35(0.60,3.06)$ & 0.47 & & \\
\hline$>0.7$ & 18 & $14(78)$ & 29 & - & & & \\
\hline \multicolumn{8}{|l|}{ PHQ-9 score } \\
\hline$\leq 6$ & 24 & $19(79)$ & 29 & - & & & \\
\hline$>6$ & 22 & $16(73)$ & 13 & $1.24(0.64,2.43)$ & 0.52 & & \\
\hline \multicolumn{8}{|l|}{ UPDRS-II (M-EDL) score } \\
\hline$\leq 13$ & 21 & $18(86)$ & 23 & - & & & \\
\hline$>13$ & 20 & $14(70)$ & 13 & $1.02(0.50,2.06)$ & 0.96 & & \\
\hline \multicolumn{8}{|l|}{ Disease duration in yrs } \\
\hline$<9$ & 53 & $34(64)$ & 23 & $1.42(0.85,2.36)$ & & & \\
\hline$\geq 9$ & 49 & $26(53)$ & 43 & - & 0.18 & & \\
\hline \multicolumn{8}{|l|}{ Surgery record } \\
\hline \multicolumn{8}{|l|}{ DBS target } \\
\hline STN & 97 & $54(56)$ & 43 & - & & - & \\
\hline GPi & 8 & $8(100)$ & 19 & $2.59(1.21,5.54)$ & 0.01 & $2.78(1.14,6.76)$ & 0.02 \\
\hline \multicolumn{8}{|l|}{ Surgery side } \\
\hline $\mathrm{Lt}$ & 63 & $33(52)$ & 46 & - & & & \\
\hline Rt & 42 & $29(69)$ & 27 & $1.50(0.91,2.48)$ & 0.11 & & \\
\hline Surgery side/dom hand & & & & & & & \\
\hline Lt surgery/rt dom hand & 59 & $32(54)$ & 46 & - & & & \\
\hline Rt surgery/lt dom hand & 12 & $9(75)$ & 21 & $1.72(0.82,3.60)$ & 0.15 & & \\
\hline Ipsilat surgery \& dom hand & 34 & $21(62)$ & 30 & $1.29(0.75,2.25)$ & 0.36 & & \\
\hline
\end{tabular}


TABLE 2. Factors associated with 5-year no-DBS survival

\begin{tabular}{|c|c|c|c|c|c|c|c|}
\hline \multirow[b]{2}{*}{ Variable } & \multirow{2}{*}{$\begin{array}{l}\text { No. of } \\
\text { Pts }\end{array}$} & \multirow{2}{*}{$\begin{array}{l}\text { DBS w/in } 5 \\
\text { Yrs, No. (\%) }\end{array}$} & \multirow{2}{*}{$\begin{array}{l}\text { KM Est Median Time, } \\
\text { No-DBS Group (mos) }\end{array}$} & \multicolumn{4}{|c|}{ Cox Hazards Model } \\
\hline & & & & Unadj HR (95\% Cl) & $\mathrm{p}$ Value & Adj HR $(95 \% \mathrm{Cl})$ & $\mathrm{p}$ Value \\
\hline \multicolumn{8}{|l|}{ Preop UPDRS score } \\
\hline UPDRS medication-off & 95 & $58(61)$ & 30 & $1.01(0.985,1.03)$ & 0.479 & & \\
\hline UPDRS medication-on & 93 & $54(58)$ & 30 & $0.997(0.969,1.03)$ & 0.818 & & \\
\hline Absolute reduction from off & 90 & $53(59)$ & 30 & $1.02(0.993,1.05)$ & 0.156 & & \\
\hline$\%$ reduction from off & 90 & $53(59)$ & 30 & $2.04(0.511,8.12)$ & 0.313 & & \\
\hline \multicolumn{8}{|l|}{ Postop UPDRS score } \\
\hline $\begin{array}{l}\text { UPDRS medication-off/stimulation- } \\
\text { on }\end{array}$ & 62 & $56(90)$ & 15 & $1.01(0.979,1.04)$ & 0.52 & & \\
\hline $\begin{array}{l}\text { Absolute reduction from preop } \\
\text { medication-off }\end{array}$ & 59 & $53(90)$ & 15 & $1.03(1.0,1.05)$ & 0.037 & & \\
\hline $\begin{array}{l}\% \text { reduction from preop medication- } \\
\text { off }\end{array}$ & 59 & $53(90)$ & 15 & $3.075(0.833,11.36)$ & 0.92 & & \\
\hline
\end{tabular}

Adj = adjusted; Est = estimated; HR = hazard ratio; $\mathrm{KM}=$ Kaplan-Meier; $\mathrm{M}-\mathrm{EDL}=$ motor experiences of daily living; Pts = patients; Unadj = unadjusted; - = reference value.

ing progression of tremors ipsilateral to the initial lead. Finally, for every unit of greater absolute UPDRS reduction following the first surgery, the likelihood of second lead placement increased $3 \%$.

We also evaluated UPDRS scores in relation to age at first DBS and duration of PD at first DBS (Table 3). Older age was not associated with preoperative off-medication UPDRS score, but it was associated with a smaller absolute reduction $(\mathrm{r}=-0.29, \mathrm{p}=0.006)$ and smaller percent reduction $(\mathrm{r}=-0.33, \mathrm{p}=0.002)$ of preoperative off- to on-medication UPDRS score. Older age was also significantly associated with a smaller absolute reduction $(\mathrm{r}=$ $-0.23, \mathrm{p}=0.032)$ and smaller percent reduction $(\mathrm{r}=-0.3$, $\mathrm{p}=0.004$ ) of preoperative off-medication to postoperative off-medication/on-stimulation UPDRS score.

Of interest, QOL variables including PHQ-9, EQ-5D, and UPDRS-II (i.e., patient-determined motor function); socioeconomic factors including median income and marital status; and sex were not found to be significant predictors of earlier second-side DBS. Additionally, as a whole, group UPDRS-III improved from the preoperative off-medication state to the postoperative on-stimulation/ off-medication state by 23.5 (SD 12.5) points or $58.8 \%$ (SD 0.21\%) after the first surgery, and 17 (SD 13.0) points or $41 \%$ (SD $0.26 \%$ ) after the second surgery, for those who had a second surgery.

\section{Discussion}

PD is a relatively common neurological disease that significantly affects QOL and mortality ${ }^{3}$ and manifests as tremor, rigidity, and/or akinesia. ${ }^{9}$ L-dopa is the mainstay of PD medical treatment, but when it leads to dyskinesias and inconsistent benefit due to nonpredictable on- and offmedication cycles, ${ }^{9}$ DBS of the STN or the GPi is a highly effective alternative. ${ }^{1,4,5,11,14,17,18}$ However, some questions concerning DBS remain incompletely explored, such as what factors indicate whether to perform initial unilateral or bilateral DBS in patients with asymmetrical disease. This study aimed to establish predictive factors of early second-side surgery following unilateral DBS for PD as a means to determine which patients with asymmetrical disease should be initially treated with bilateral rather than unilateral DBS. Via this investigation, we could improve the preoperative decision-making process regarding unilateral versus bilateral surgery by learning from historical cases.

We hypothesized that patients with worse motor symptoms at baseline, better L-dopa responsiveness, worse baseline QOL and depression, shorter disease duration, and younger age at first surgery would be more likely to receive a second lead and in a shorter time period. We found a 5-year second-surgery incidence of 59\% within our cohort. This was very similar to the 3.5-year secondsurgery incidence of $52 \%$ found by Taba et al. ${ }^{15}$

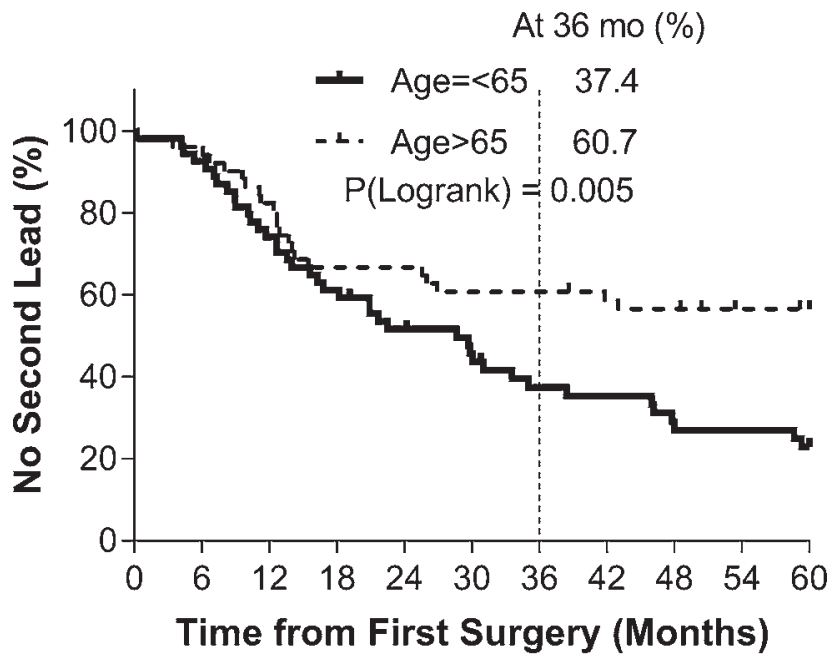

FIG. 1. Kaplan-Meier analysis showing that younger age is a significant predictor of early second-side DBS surgery. $\mathrm{mo}=$ months. 


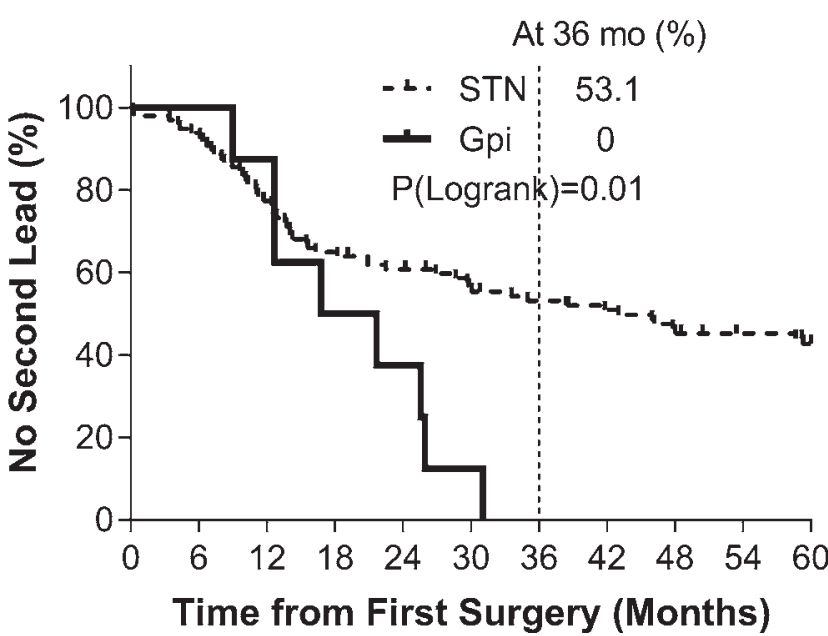

FIG. 2. Kaplan-Meier analysis showing DBS target in relation to likelihood of second surgery.

Within our cohort, younger age, greater difference between off-medication preoperative and postoperative UPDRS-III scores, and GPi target were all found to be significant predictors of early second-side surgery following unilateral DBS. Larger preoperative medication-off to medication-on UPDRS-III reduction also trended toward significance. Our findings differ from previous ones by Taba et al., who found that the baseline motor score was the most important factor in establishing whether a patient would go on to have a second lead placed and that patients with stimulation of the STN rather than the GPi were significantly more likely to eventually receive a second lead. ${ }^{15}$ Greater preoperative difference between off-medication and on-medication UPDRS-III has previously been identified as a predictive factor for greater QOL improvement following DBS for PD. ${ }^{6}$ Frizon et al. ${ }^{6}$ indicated that for every $1 \%$ of additional preoperative on-medication versus off-medication increase in UPDRS-III change, patient improvement odds increased by $4.5 \%$. This corroborates our finding that greater decreases in the UPDRS-III score from pre- to postoperative states following unilateral DBS lead to increased chances of undergoing second surgery, probably due to increased confidence in a positive outcome. However, because response to unilateral lead placement is not known preoperatively, L-dopa responsiveness before surgery acts as a potential surrogate for this predictive factor.

The finding that younger patients were more likely to receive a second lead could be due to the potential for more years of life with the disease and therefore more willingness to undergo a second surgery to improve their QOL long-term. Younger patients may also experience greater initial improvement in motor function and QOL after DBS compared to older patients ${ }^{2}$ (Table 3). Meanwhile, older patients may elect not to pursue second-side surgery due to factors such as advancing cognitive issues, other medi$\mathrm{cal} /$ personal comorbidities, and potentially more effective postoperative medication control than younger patients. ${ }^{8}$ Additionally, because PD is characteristically a disease of older individuals, ${ }^{3}$ younger patients may have been in earlier stages of their disease at the time of their initial
TABLE 3. Association of UPDRS-III score with age and duration of PD at first DBS

\begin{tabular}{lcr}
\hline \multicolumn{1}{c}{ UPDRS-III Score } & Age & PD Duration \\
\hline Preop medication-off & $-0.004(0.967)$ & $0.14(0.191)$ \\
\hline $\begin{array}{l}\text { Preop medication-off to } \\
\text { medication-on }\end{array}$ & & \\
\hline Absolute reduction & $-0.29(0.006)$ & $0.16(0.143)$ \\
\hline$\%$ reduction & $-0.33(0.002)$ & $0.16(0.149)$ \\
\hline $\begin{array}{l}\text { Preop medication-off to postop } \\
\text { medication-off/stimulation-on }\end{array}$ & & \\
\hline Absolute reduction & $-0.23(0.032)$ & $0.03(0.781)$ \\
\hline$\%$ reduction & $-0.3(0.004)$ & $-0.07(0.518)$ \\
\hline
\end{tabular}

Values are expressed as rho ( $p$ value).

unilateral surgery. Thus, younger patients' disease may be more likely to worsen over time, leading them to undergo a second surgery. However, Miller-Patterson et al. have recently shown that disease asymmetry in PD does not seem to change over a period of 5 years. ${ }^{10}$ Despite this fact, overall disease progression involving both sides over time may still lead to worsening contralateral symptoms that eventually warrant surgery.

Finally, a GPi target being a significant predictor of early second surgery compared to an STN target is probably a product of the intentions of treatment. The GPi was disproportionately recommended by our group over STN for patients who suffered significantly from dyskinesias. ${ }^{13}$ The typical goal of GPi stimulation is to reduce dyskinesias from L-dopa. ${ }^{13}$ Unlike patients treated with STN DBS, patients implanted with GPi DBS leads are not prescribed lower L-dopa dosages to prevent dyskinesias from developing postoperatively. ${ }^{16}$ Thus, if patients are maintained on their preoperative medication doses, they are likely to develop contralateral dyskinesias, warranting surgery on the contralateral side. This hypothesis was supported on further analysis of the GPi group, because 6 of the 8 patients who underwent GPi stimulation received a contralateral lead due to persistent or worsening dyskinesia ipsilateral to the initial lead.

Data from this study have been longitudinally incorporated into our practice over time. This group has found that STN DBS is the preferable target overall for PD and works very well for most patients in terms of motor outcomes, reduction of dopaminergic medication, ease of programming, and patient satisfaction. For patients undergoing GPi stimulation for dyskinesia-predominant symptoms, bilateral implantation in the intraoperative MRI suite is preferred. In keeping with these accumulated data, our group performs unilateral STN implantation less frequently due to the recognition that many patients were returning for second-side surgery. The primary exception for this trend has been seen in tremor-predominant patients, and patients with primarily unilateral tremor are still offered unilateral STN DBS for symptom management.

\section{Limitations and Strengths}

This study has several limitations. First, the study was limited by its design as a retrospective cohort analysis, which intrinsically contains increased levels of confound- 
ing and bias compared to most prospective designs. Due to its retrospective nature via chart review, the study was also subject to loss to follow-up, which was controlled via censoring patients at last follow-up or death. Although we attempted to control confounding in this study by the inclusion of multiple variables and examination of complications and comorbidities, unavailable data due to lack of collection retrospectively may have affected the results of this study. We also did not track individual reasons for second lead placement in this study. However, based on experience in our practice, patients who respond well to unilateral DBS frequently will request second-side treatment without prompting. In some cases, patients notice that symptoms on the untreated side are more bothersome after treatment. An additional limitation is that the total of 1011 patients in the study cohort from which the 105 individually reviewed patients with unilateral DBS were derived was based on diagnostic and procedural codes, and so there may be a minor error in the total number of patients undergoing DBS for PD over the study period. Despite the limitations of this study, our cohort of 105 patients is one of the larger cohorts in a study of patients with PD post-DBS.

\section{Conclusions}

In this study we found that younger age, greater offmedication improvement in UPDRS-III score after DBS, and GPi target were predictors of early second-side surgery following unilateral DBS for PD. In the future, larger multicenter retrospective studies on this topic or prospective studies may be useful in determining more predictive factors that can further improve the neurosurgeon-patient decision process.

\section{References}

1. Benabid AL, Chabardes S, Mitrofanis J, Pollak P: Deep brain stimulation of the subthalamic nucleus for the treatment of Parkinson's disease. Lancet Neurol 8:67-81, 2009

2. Dafsari HS, Reker P, Stalinski L, Silverdale M, Rizos A, Ashkan K, et al: Quality of life outcome after subthalamic stimulation in Parkinson's disease depends on age. Mov Disord 33:99-107, 2018

3. de Lau LM, Breteler MM: Epidemiology of Parkinson's disease. Lancet Neurol 5:525-535, 2006

4. Fasano A, Daniele A, Albanese A: Treatment of motor and non-motor features of Parkinson's disease with deep brain stimulation. Lancet Neurol 11:429-442, 2012

5. Follett KA, Weaver FM, Stern M, Hur K, Harris CL, Luo P, et al: Pallidal versus subthalamic deep-brain stimulation for Parkinson's disease. N Engl J Med 362:2077-2091, 2010

6. Frizon LA, Hogue O, Achey R, Floden DP, Nagel S, Machado AG, et al: Quality of life improvement following deep brain stimulation for Parkinson disease: development of a prognostic model. Neurosurgery 85:343-349, 2019

7. Goetz CG, Stebbins GT, Tilley BC: Calibration of unified Parkinson's disease rating scale scores to Movement Disorder Society-unified Parkinson's disease rating scale scores. Mov Disord 27:1239-1242, 2012

8. Hanna JA, Scullen T, Kahn L, Mathkour M, Gouveia E, Garces J, et al: Comparison of elderly and young patient populations treated with deep brain stimulation for Parkinson's disease: long-term outcomes with up to 7 years of follow-up. J Neurosurg 131:807-812, 2019

9. Lang AE, Lozano AM: Parkinson's disease. First of two parts. N Engl J Med 339:1044-1053, 1998
10. Miller-Patterson C, Buesa R, McLaughlin N, Jones R, Akbar U, Friedman JH: Motor asymmetry over time in Parkinson's disease. J Neurol Sci 393:14-17, 2018

11. Odekerken VJ, van Laar T, Staal MJ, Mosch A, Hoffmann CF, Nijssen PC, et al: Subthalamic nucleus versus globus pallidus bilateral deep brain stimulation for advanced Parkinson's disease (NSTAPS study): a randomised controlled trial. Lancet Neurol 12:37-44, 2013

12. Petraglia FW III, Farber SH, Han JL, Verla T, Gallis J, Lokhnygina $\mathrm{Y}$, et al: Comparison of bilateral vs. staged unilateral deep brain stimulation (DBS) in Parkinson's disease in patients under 70 years of age. Neuromodulation 19:31-37, 2016

13. Ramirez-Zamora A, Ostrem JL: Globus pallidus interna or subthalamic nucleus deep brain stimulation for Parkinson disease: a review. JAMA Neurol 75:367-372, 2018

14. Rodriguez-Oroz MC, Obeso JA, Lang AE, Houeto JL, Pollak $\mathrm{P}$, Rehncrona S, et al: Bilateral deep brain stimulation in Parkinson's disease: a multicentre study with 4 years follow-up. Brain 128:2240-2249, 2005

15. Taba HA, Wu SS, Foote KD, Hass CJ, Fernandez HH, Malaty IA, et al: A closer look at unilateral versus bilateral deep brain stimulation: results of the National Institutes of Health COMPARE cohort. J Neurosurg 113:1224-1229, 2010

16. Vitek JL: Deep brain stimulation for Parkinson's disease. A critical re-evaluation of STN versus GPi DBS. Stereotact Funct Neurosurg 78:119-131, 2002

17. Weaver FM, Follett K, Stern M, Hur K, Harris C, Marks WJ $\mathrm{Jr}$, et al: Bilateral deep brain stimulation vs best medical therapy for patients with advanced Parkinson disease: a randomized controlled trial. JAMA 301:63-73, 2009

18. Williams A, Gill S, Varma T, Jenkinson C, Quinn N, Mitchell R, et al: Deep brain stimulation plus best medical therapy versus best medical therapy alone for advanced Parkinson's disease (PD SURG trial): a randomised, open-label trial. Lancet Neurol 9:581-591, 2010

\section{Disclosures}

Dr. Machado receives consulting/speaking fees from St. Jude Medical, Inc., and may receive future financial benefits from CardioNomics, Autonomic Technologies, Inc., and Enspire DBS related to intellectual property. Dr. Walter receives consulting/ speaking fees from Medtronic, Inc., Adamas Pharmaceuticals, Inc., Neurocrine Biosciences, Inc., US WorldMeds, LLC, and Teva Neuroscience.

\section{Author Contributions}

Conception and design: Golubovsky, Frizon, Nagel. Acquisition of data: Golubovsky, Momin, Shao, Lee. Analysis and interpretation of data: Golubovsky, Li, Momin, Frizon, Hogue, Walter, Machado, Nagel. Drafting the article: Golubovsky. Critically revising the article: Golubovsky, Li, Frizon, Hogue, Walter, Machado, Nagel. Reviewed submitted version of manuscript: Golubovsky, Li, Frizon, Hogue, Walter, Machado, Nagel. Approved the final version of the manuscript on behalf of all authors: Golubovsky. Statistical analysis: Li, Hogue. Administrative/technical/material support: Machado, Nagel. Study supervision: Nagel.

\section{Supplemental Information}

\section{Previous Presentations}

This work was presented in part at the annual meeting of the AANS, held April 13-17, 2019, in San Diego, CA.

\section{Correspondence}

Joshua L. Golubovsky: Cleveland Clinic Lerner College of Medicine of Case Western Reserve University, Cleveland, $\mathrm{OH}$. goluboj@ccf.org. 